\section{Um método chamado Pinotti: sal medicamentoso, malária e saúde internacional (1952-1960)}

\section{A method called Pinotti: medicated salt, malaria, and international health (1952-1960)}

Renato da Silva

Professor dos Programas de Pós-graduação do Ensino de Ciências e de Letras e Ciências Humanas/Escola de Educação, Ciências, Letras e Humanidades/Universidade Unigranrio.

Rua Professor José de Sousa Herdy, 1160 25071-202 - Duque de Caxias - RJ - Brasil redslv@hotmail.com

\section{Gilberto Hochman}

Pesquisador da Casa de Oswaldo Cruz/ Fundação Oswaldo Cruz (COC/Fiocruz); professor do Programa de Pós-graduação em História das Ciências e da Saúde/COC/Fiocruz. Av. Brasil, 4036/403

21040-361 - Rio de Janeiro - RJ - Brasil hochman@coc.fiocruz.br

Recebido para publicação abril de 2010. Aprovado para publicação em abril de 2011.
SILVA, Renato da; HOCHMAN, Gilberto. Um método chamado Pinotti: sal medicamentoso, malária e saúde internacional (1952-1960). História, Ciências, Saúde - Manguinhos, Rio de Janeiro, v.18, n.2, abr.-jun. 2011, p.519-543.

\section{Resumo}

Analisa a criação, a recepção e o abandono do método Pinotti de combate à malária: sal de cozinha misturado com cloroquina. Idealizado no início da década de 1950 pelo malariologista brasileiro Mario Pinotti como ação profilática e terapêutica contra a malária, foi testado durante a primeira metade daquela década e utilizado no Brasil entre 1959 e 1961, como parte da campanha de erradicação da malária coordenada pela Organização Mundial da Saúde. Conquistou reconhecimento no cenário internacional da saúde, sofreu críticas e foi testado em outros países até meados dos anos 1960. Argumentamos que, no Brasil, o abandono foi devido, sobretudo, ao ocaso político de seu criador, a partir de 1960.

Palavras-chave: malária; Mario Pinotti (1894-1972); erradicação; sal medicamentoso; Organização Mundial da Saúde.

\section{Abstract}

The article analyzes the creation, acceptance, and abandonment of a means of fighting malaria known as the Pinotti method: kitchen salt mixed with chloroquine. The early 1950s brainchild of Brazilian malariologist Mario Pinotti, this method was intended to both prevent and treat malaria. Chloroquine-medicated salt was tested during the first half of that decade and used in Brazil from 1959 through 1961 as part of a malaria eradication campaign coordinated by the World Health Organization. The method won recognition on the world health stage, drew criticism, and underwent testing in other countries until the mid-1960s. We argue that Brazil's abandonment of the method was primarily due to the political decline of its creator, which began in 1960.

Keywords: malaria; Mario Pinotti (18941972); eradication; medicated salt; World Health Organization. 
$\mathrm{O}$ pós-Segunda Guerra Mundial foi marcado por grande otimismo em relação à utilização de inseticidas de ação residual contra os vetores de doenças infectocontagiosas. Resultados expressivos no controle da malária foram anunciados já no final da década de 1940. Contudo, no início dos anos 1950, os malariologistas começaram a preocupar-se com a possibilidade de que a principal arma contra tal doença, o diclorodifenil-tricloroetano (DDT), perdesse sua eficácia, devido à crescente resistência dos mosquitos ao inseticida. Para muitos, a solução seria converter os programas de controle de malária (de longo prazo) em programas de erradicação da malária, uma meta a ser alcançada em curto prazo (Packard, 1998, 2007). Nesse cenário preocupante, o médico sanitarista Mario Pinotti (1894-1972), personagem proeminente da saúde pública e da malariologia brasileira nas décadas de 1940 e 1950, apresentou uma alternativa promissora: sal de cozinha misturado com cloroquina, o antimalárico mais utilizado na terapêutica da malária nos 15 anos que se seguiram ao final da Segunda Guerra (Slater, 2004). O método, que ficaria conhecido pelo sobrenome de seu idealizador, foi apresentado para ser utilizado tanto de modo complementar ao DDT quanto como a única estratégia profilática e terapêutica, quando o emprego do inseticida não fosse possível. A grande repercussão do método Pinotti no campo da saúde internacional pode ser avaliada a partir de debates, críticas e apresentações em congressos, notícias em jornais, documentos oficiais e correspondência entre especialistas da Organização Mundial da Saúde (OMS) e malariologistas brasileiros e estrangeiros que participavam das pesquisas laboratoriais e de campo sobre esse e outros métodos de combate à malária.

A proposta de utilização do sal medicamentoso como parte dos esforços brasileiros de controle e erradicação da malária no pós-Segunda Guerra Mundial tem sido reconhecida, tanto por memorialistas como por historiadores, como episódio revelador dos caminhos e dilemas da saúde pública nacional e internacional na década de 1950 (Moraes, 1990; Hochman, Mello, Santos, 2002; Paulini, 2004; Hochman, 2008, 2010). Porém são poucos os trabalhos que, no campo da história da saúde, se debruçaram detalhadamente sobre esse método brasileiro de controle da malária, de modo a analisar os debates que o cercaram, os processos concretos de sua implementação e suas repercussões no Brasil e no exterior. Em particular, argumentamos que a trajetória do sal medicamentoso contra a malária deve ser compreendida, em grande parte, pela sua associação à trajetória profissional e política de seu criador, revelando as intrincadas relações entre ações sanitárias e política na experiência democrática brasileira iniciada em 1945 e interrompida pelo golpe civil-militar de 1964 . Além disso, interessa-nos ressaltar que a atenção e o interesse despertados pelo método ultrapassam a dimensão específica de sua utilização como política antimalárica no Brasil e devem ser compreendidos, fundamentalmente, tendo em vista a centralidade conferida ao tema da erradicação da malária na agenda das organizações internacionais da saúde, da indústria química e farmacêutica e dos organismos de cooperação bilateral.

\section{A trajetória do sanitarista e político Mario Pinotti: do Serviço Nacional de Malária ao Ministério da Saúde (1942-1960)}

Mario Pinotti nasceu na cidade de Brotas, no estado de São Paulo, em 21 de janeiro de 1894. Completou o curso de Farmácia pela Faculdade de Ouro Preto em 1914. Em 1918 
diplomou-se médico pela Faculdade de Medicina do Rio de Janeiro. No ano seguinte ocupou o cargo de químico auxiliar do Serviço de Fiscalização do Leite, no Rio de Janeiro, e depois de chefe do posto do Serviço de Profilaxia da capital federal. Entre 1920 e 1923 foi inspetor sanitário, tendo sido nomeado intendente (prefeito) de Nova Iguaçu em 1922 e, um ano depois, de São Gonçalo, num movimento que já indicava a dupla atuação como sanitarista e político que marcaria sua vida profissional. Em 1924 e 1925, Pinotti estudou na Escola de Malária, em Netuno, na Itália, com bolsa de estudos da Fundação Rockefeller. ${ }^{1}$ Em 1928 assumiu o cargo de chefe do Serviço de Profilaxia Rural no estado do Rio de Janeiro e, em 1930, foi nomeado inspetor do Serviço de Profilaxia da Febre Amarela, já no primeiro governo de Getúlio Vargas (Hochman, 2007, p.1013; Moraes, 1990, p.259).

Em 26 de agosto de 1942, assumiu a direção do Serviço Nacional de Malária (SNM)², então criado por ocasião de uma importante reforma do Ministério da Educação e Saúde (MES), que viria a consolidar as diretrizes da política de saúde empreendida por Gustavo Capanema, destinadas a ampliar as estruturas administrativas e o alcance das ações sanitárias do poder federal (Fonseca, 2007). Pinotti ficaria à frente do SNM durante 14 anos, em cargo que o consagraria como o principal personagem da saúde pública brasileira do período e que o levou a assumir o Ministério da Saúde em 1954, no final do segundo Governo Vargas, e em 1958, no governo Kubitschek (Moraes, 1990). Foi também representante do governo brasileiro nos $4^{\text {os }}$ Congressos Internacionais de Medicina Tropical e Malária, realizados em Washington, em 1948. No mesmo ano participou da criação da Revista Brasileira de Malariologia, periódico do SNM e principal veículo de divulgação da malariologia brasileira, em particular dos trabalhos de Pinotti e seus colaboradores. O diretor do SNM esteve à frente, ainda, da criação do Instituto de Malariologia (IM), órgão do SNM destinado à pesquisa e ao ensino especializado em malária, com setores dedicados à parasitologia, entomologia, engenharia sanitária, inseticidas, patologia e terapêutica. Em 1952 e 1953, Pinotti presidiu a Sociedade Brasileira de Higiene e foi um dos artífices do Programa de Saúde do candidato à Presidência Juscelino Kubitschek, que propunha como prioridade o combate das endemias rurais (Programa..., 1955; Hochman, 2009). Foi nomeado primeiro diretor do Departamento Nacional de Endemias Rurais (DNERu), criado em março de 1956, e tornou-se presidente do Grupo de Trabalho de Controle e Erradicação Malária (GTEM) em 1958. Nesse mesmo ano alcançou o topo de sua carreira política quando, pela segunda vez, se tornou ministro da Saúde e responsável pela política de saúde do governo federal, cargo que ocuparia até agosto de 1960 (Hochman, 2007; Moraes, 1990, p.262). ${ }^{3}$

Pinotti apresentou, em 1952, um novo método de combate à malária, o sal de cozinha cloroquinado, que muito rapidamente ficou conhecido como método Pinotti, como já assinalado. A associação do método a seu nome evidenciava e reforçava o prestígio científico e político de seu idealizador no Brasil e no exterior. A proclamada redução drástica da malária no início da década de 1950 foi celebrada como resultado das novas descobertas da ciência (inseticidas de ação residual e antimaláricos) e como conquista do sanitarismo brasileiro associada politicamente à liderança de Pinotti (Programa..., 1955; Rachou, 1956). Segundo Rostan Soares, colaborador de Pinotti no Instituto de Malariologia, em cinco anos de uso generalizado do DDT, com dedetizações domiciliares no combate às espécies de anofelinos vetores da malária, teria sido possível ao SNM obter redução de 95\% a 97\% 
da doença em toda a área malarígena do país. ${ }^{4}$ Mas o DDT não foi a única arma no combate à malária pós-Segunda Guerra. A cloroquina, particularmente o difosfato de cloroquina, um dos seus sais comercialmente conhecido como Aralen, se teria mostrado superior a outras drogas antimaláricas por ser capaz de dar respostas profiláticas e terapêuticas (Bustamante, 1958, p.84). Pinotti foi entronizado, ainda vivo, no panteão da saúde pública brasileira como sucessor de uma dinastia formada por Oswaldo Cruz, Belisário Pena, Emílio Ribas e Carlos Chagas (Programa..., 1955, p.53; Hochman, 2009).

Aclamado no Brasil, Pinotti foi indicado por prestigiados malariologistas e entusiastas da erradicação da malária, como o venezuelano Arnaldo Gabaldón, para receber o Prêmio Darling. ${ }^{5}$ Segundo Gabaldón, a criação do método Pinotti seria a mais importante contribuição no combate à malária na década de 1950 (Gabaldón, 17 fev. 1956). Em 1957 Pinotti tornou-se membro da Academia Nacional de Medicina (Moraes, 1990). Dois anos depois, publicou o livro Vida e morte do brasileiro: saúde e doença no Brasil, uma compilação de suas análises sobre a situação sanitária do país. Nelas, em sintonia com as discussões travadas no cenário internacional - especialmente na OMS - sobre o 'círculo vicioso da doença e da pobreza' (Myrdall, 1952; Winslow, 1955), defendia a ideia de que os índices de saúde e doença de um povo estão diretamente relacionados ao grau de desenvolvimento do país (Pinotti, 1959). ${ }^{6}$ Em mais um indício revelador de como sua atuação como sanitarista era estreitamente relacionada à sua atuação e prestígio na esfera da política, em 1959 uma carta assinada por 240 deputados federais indicou o nome de Pinotti ao Prêmio Nobel de Medicina (Moraes, 1990, p.354-358).

Pinotti deixou o governo Kubitschek em agosto 1960, devido a suas relações com o Partido Social Progressista (PSP) de Ademar de Barros e aos ajustes políticos que antecederam as eleições de outubro de 1960. Cabe destacar os conflitos com Jânio Quadros, então governador de São Paulo e candidato à Presidência da República em 1960, disputada também por Barros, principal adversário de Quadros na política paulista (Sampaio, 1982). Para Maurício Medeiros, ministro da Saúde a quem Pinotti sucedeu, Ademar de Barros teria sido o responsável pelo afastamento de Pinotti e pela perda de representação do Partido Social Progressista (PSP) no governo. Barros vinha liderando uma campanha contra o general Henrique Lott, candidato do partido de Juscelino Kubitschek - o Partido Social Democrático (PSD) -, à sucessão presidencial. Juscelino teria reagido afastando Pinotti do governo e instaurando um inquérito para apurar supostas irregularidades no Ministério da Saúde, controlado pelo PSP. Durante a Presidência de Jânio Quadros, Pinotti e colaboradores foram alvos de acusações e inquérito, o que fez o médico retirar-se definitivamente da vida pública. Alguns anos depois, durante o regime militar, o inquérito foi arquivado por falta de provas. Mario Pinotti morreu no dia 3 março de 1972, longe da política e da saúde pública (CPDOC, s.d.).

\section{O DDT: do otimismo à preocupação}

Ao final da Segunda Guerra Mundial, o DDT foi apresentado, pelos cientistas, como a arma mais eficaz de combate à malária. O produto foi originalmente sintetizado em 1854, mas sua eficácia foi descoberta pelo cientista suíço Paul Muller, que ganharia o Prêmio 
Nobel de Medicina em 1948. Durante a guerra, a empresa suíça Geigy, subsidiária da alemã Bayer, desenvolveu o inseticida de ação residual utilizado inicialmente para controlar uma epidemia de tifo. O DDT foi testado no período da guerra e, com o fim do conflito, seu uso tornou-se rapidamente rotineiro na saúde pública, na agricultura e na vida domiciliária. Os malariologistas teriam ficado entusiasmados com os resultados alcançados com o DDT, cujo emprego reduziu em curto prazo os casos de malária em vários países (Dunlap, 1981; Russell, 2001; Cueto, 2007).

O DDT aparentemente teve maior impacto nos países cujas condições sanitárias eram mais desenvolvidas, isto é, países ou regiões em que foram realizadas obras de engenharia hidráulica e drenagem de terras alagadas, e houve recursos para promover tratamento em massa e manter ativo um serviço de controle e vigilância da malária - locais em que o mosquito não teria condições de desenvolver nichos ecológicos alternativos para reprodução. Nesses casos, o DDT rompeu definitivamente a já enfraquecida cadeia de transmissão da malária (Camargo, 1995; Humphreys, 1996). O DDT foi então considerado uma arma eficiente contra a malária, porque interrompia definitivamente a transmissão da doença; e, de fato, em muitas áreas do mundo a malária declinou (Farid, 1966, p.5). Os impactos positivos de sua utilização contra os vetores da doença levaram as autoridades de saúde internacional a acreditar que a erradicação da malária seria possível em curto prazo de tempo: com o DDT era possível o domínio do homem sobre a malária. ${ }^{7}$

Em 1947 teve início a utilização em larga escala do DDT no Brasil (Hochman, Mello, Santos, 2002, p.269). A primeira grande campanha ocorreu no estado do Rio de Janeiro e incluía 1.821 localidades de trinta municípios (quase a totalidade de municípios do estado), incluída a capital federal, e foi considerada um modelo de ação para o resto do país. Segundo os especialistas de então, o inseticida combinava qualidades que não haviam sido apresentadas em nenhuma outra droga antimalárica: alta toxidade para os mosquitos da malária, baixa toxidez para o aplicador, ação prolongada com estabilidade química satisfatória e baixo custo (Paulini, 2004). Para René Rachou (1956), pesquisador do Instituto de Malariologia e um dos principais colaboradores de Mario Pinotti, a utilização massiva dos inseticidas de efeito residual teria produzido resultados extraordinários, que superavam em muito outros métodos convencionais de combate à malária. No entanto, em 1962 emergiu uma crítica de natureza bastante diferente daquela ocorrida em meados da década de 1950, relacionada à resistência dos vetores resultante da má e prolongada utilização do DDT. O inseticida passaria a ser condenado por causa de seus efeitos negativos no homem e no ambiente, que seriam superiores aos benefícios para a agricultura e a saúde. ${ }^{8}$

Mas na década de 1950 o clima ainda era otimista. Na Conferência Regional de Malária Para os Países da Europa e do Leste do Mediterrâneo, organizada pela OMS em Atenas, em 1956, foi ressaltado que os quatro milhões de casos de malária ocorridos anualmente no sul da Europa, da Espanha à Bulgária, antes do aparecimento do DDT teriam sido reduzidos, ao fim da Segunda Guerra Mundial, a dez mil casos por ano. Nos países ao leste do Mediterrâneo, os programas de controle da malária com inseticidas residuais reduziram de quarenta milhões, em 1949, para quatorze milhões os casos de malária (Bustamante, 1958, p.83).

O desenvolvimento de resistência a inseticidas por algumas espécies de vetores e sua possível ampliação para outros transmissores chamou a atenção dos especialistas em malária 
(Packard, 2007). A doença sempre esteve no topo da agenda da saúde internacional, no entanto a partir da década de 1950 intensificou-se o discurso sobre sua gravidade. Os malariologistas começaram a alertar que a continuidade dos programas de controle agravaria a situação, já que a arma mais eficiente, o DDT, poderia simplesmente perder seu poder de combate (Packard, 1997). Emergiu então, na arena internacional e nacional, o argumento de que os programas de controle de longo prazo deveriam ser substituídos por programas de erradicação de curto prazo. Os estudos sobre a resistência dos vetores ao DDT estiveram na pauta central da 14 $4^{a}$ Conferência Sanitária Pan-americana, realizada em 1954 em Santiago do Chile, e da 8a Assembléia Mundial da Saúde, que teve lugar em 1955, na Cidade do México. Desses encontros resultaram propostas e recomendações aos países em que a malária era endêmica, para que convertessem os programas de controle, caso existissem, em programas de erradicação (Packard, 1998, p.219, 2007; Suddiqi, 1995; Cueto, 2007).

No cenário nacional, em 1955 a questão da resistência dos vetores da malária ao DDT não era percebida ainda como problema pelos malariologistas brasileiros. No mesmo ano, Juscelino Kubitschek, então candidato à Presidência, apresentou seu Programa de Saúde Pública, um documento político que contou com a contribuição decisiva de Mario Pinotti (Hochman, 2009). Nele, a malária era apresentada como um problema sanitário em vias de ser solucionado, graças a ações continuadas de controle por meio de DDT e antimaláricos. A erradicação da doença seria o resultado 'natural' desse bem-sucedido processo, e não se colocava a necessidade de um programa exclusivo de erradicação (Programa..., 1955, p.16; Pinotti, 1956a). Dois anos depois, Pinotti (1957) sugeriu que os mosquitos já estariam adquirindo resistência ao inseticida, devido à utilização sem planejamento eficaz.

Na perspectiva de Kubitschek e Pinotti, a malária seria um problema circunscrito a algumas regiões do Brasil, como a Amazônia, considerada um obstáculo ao sucesso do programa de controle em grande parte do território nacional já no início da década de 1950. Em estudo de 1955, "Objetivos da pesquisa sobre o sal cloroquinado e o programa adotado nas observações com doentes de malária hospitalizados", Rostan Soares reconhecia os resultados positivos da utilização do DDT logo após o início de seu uso contra a malária. Porém, apontava problemas específicos nas localidades com pouco adensamento populacional e residências precárias, nas quais o inseticida não poderia ser utilizado de modo eficaz (Soares, 1955). ${ }^{9}$ Assim, a proposta de um método alternativo ou complementar ao DDT pela malariologia brasileira tinha motivações diferentes daquela apontada por especialistas das agências da saúde internacional, qual seja, a crescente resistência de espécies de anofelinos ao inseticida mais eficaz.

\section{Cobertura total: aonde o DDT não chega, o sal cloroquinado alcança}

Os malariologistas brasileiros procuravam, desde o final da década de 1940, um método para combater a malária em áreas aonde a utilização do DDT era pouco viável. O sal de cozinha cloroquinado, a ser distribuído gratuitamente nessas áreas, foi apresentado como método complementar à ação dos inseticidas. Essa proposta foi inspirada na obrigatoriedade da mistura do iodo ao sal de cozinha para combater o bócio endêmico, em discussão no Brasil desde o Estado Novo. A obrigatoriedade da iodação do sal de cozinha foi estabelecida 
por lei em 1953 e começou a ser efetivamente implementada em 1957, durante o governo de Juscelino Kubitschek (Portugal, 2008; Hochman, 2010).

A ideia da cloroquinização do sal também foi orientada por pesquisas baseadas em experiências com a cloroquina como supressivo ${ }^{10}$, em doses semanais e únicas. Esse efeito supressivo da cloroquina fora testado, no final dos anos 1940, por pesquisadores estrangeiros como Godsmith, em Assan; Boucet, no Congo Belga e no Panamá; Boldt e Goldvine, que teriam comprovado o valor da profilaxia semanal; Berbarian, na Síria; e Safth, Pacleer, Kierlaud e MaCreight, que obtiveram, em diversas áreas do mundo, resultados considerados excelentes (Pinotti, 1957; Slater, 2009).

Segundo Pinotti, além da resistência dos vetores ao DDT, havia outras razões para se buscar um novo método de combate à malária: (a) em algumas regiões, a transmissão se dava preferencialmente fora dos domicílios, o que inviabilizava a aplicação do inseticida; (b) as características de algumas moradias, típicas de certas regiões, como ausência de paredes, a exemplo das habitações na Amazônia; (c) o comportamento nômade de algumas populações; (d) a grande extensão territorial do país; e (e) falhas nas ações de borrifamento de DDT. O diretor do SNM estruturou, assim, um plano específico de enfrentamento da malária no país. ${ }^{11}$

Os primeiros testes realizados por Pinotti e Soares indicavam a viabilidade do uso da cloroquina misturada ao sal de cozinha, na alimentação diária. Basicamente, esses testes tinham a intenção de verificar a resistência da mistura à degradação, tendo em vista o longo tempo de armazenagem e a transformação da mistura decorrente de grandes variações do $\mathrm{pH}$. O método denominado sal cloroquinado utilizaria o antimalárico em doses que possibilitassem um emprego econômico e por longos períodos. Testes físicos e químicos demonstraram que o sal cloroquinado resistia por longo período à armazenagem, ao transporte e às condições de cozimento (em meio de $\mathrm{pH} 4-7$, por três a quatro horas, sem alterações do medicamento), o que evidenciava estabilidade química suficiente para ser empregado na alimentação diária. Além desses dois aspectos, realizaram-se pesquisas para avaliar os efeitos cumulativos da ingestão de cloroquina, os fenômenos secundários que porventura a mistura viesse a produzir, o paladar do sal e o modo de sua distribuição (Pinotti, 1957; Pinotti, Soares, 1956).

As pesquisas tiveram início em 1952, em pacientes internados nos hospitais de Neurossífilis e Pedro II, do Serviço Nacional de Doenças Mentais, e Evandro Chagas, do Instituto Oswaldo Cruz. Essas primeiras experiências utilizavam a dose de 0,045g/base e trataram 68 doentes, sendo 35 deles com objetivos terapêuticos e 33 com fins preventivos. Em seguida foram feitos testes utilizando a dose diária de $0,030 \mathrm{~g} / \mathrm{base}$ em 31 doentes, sendo 23 ações terapêuticas e oito de profilaxia. As pesquisas continuaram reduzindo a dose diária, que passou para 0,020g/base, utilizada em 44 doentes, sendo 23 ações terapêuticas e 21 de profilaxia. Com o objetivo de avaliar a dose mínima (limite) do efeito da cloroquina como antimalárico, testou-se também a dose $0,010 \mathrm{~g} / \mathrm{base}$ em dois doentes. Além dessas doses realizadas por período de tempo curto, uma ou duas semanas no máximo, ocorreram pesquisas também em pacientes que receberam a dose diária de $0,045 \mathrm{~g} / \mathrm{base}$ do difosfato de cloroquina por dois anos, com o objetivo de testar (observar) a intoxicação; o resultado foi negativo. Averiguou-se a possibilidade do aparecimento de resistência ao parasita a 
doses fracionadas da medicação; essa resistência não teria sido observada pelos pesquisadores (Pinotti, 1957, p.8).

Durante a fase de testes e experiências, o trabalho de campo e a distribuição do sal cloroquinado foram realizados em áreas endêmicas com restrições ao uso do DDT, sendo constituídos por: (a) distribuição do sal cloroquinado aos comerciantes, com troca de todo o sal em estoque; (b) distribuição da nova droga antimalárica aos moradores das regiões amazônicas; (c) alerta e pedido aos atacadistas fornecedores para colaborarem e não distribuírem o sal comum, substituído então pelo cloroquinado. Nenhum outro medicamento antimalárico foi utilizado nesse período de experiência. Para Pinotti, outra fase importante da pesquisa consistia em visitas às residências e na distribuição direta do sal cloroquinado, que possibilitaram maior controle das ações. Cada casa tinha uma ficha de consumo de sal cloroquinado. A presença da cloroquina era testada periodicamente, por meio de $1 \mathrm{~g}$ a $2 \mathrm{~g}$ de sal (uma colher de chá) em um tubo de ensaio com $5 \mathrm{ml}$ de água limpa. Depois que a solução era agitada para dissolver o sal, adicionavam-se três a cinco gotas de iodo ( $10 \mathrm{~g}$ de iodo metálico e $20 \mathrm{~g}$ de iodo de potássio para 1 litro de água). Na presença de cloroquina, essa solução desenvolveria uma coloração marrom-escuro; sem cloroquina, a cor seria amarelo-claro.

Segundo Pinotti, a concentração da droga no sal antimalárico preparado de acordo com os resultados das pesquisas deveria ser de $0,33 \%$ de difosfato de cloroquina, ou seja, $0,2 \%$ de base de cloroquina. Os estudos apontaram também que o consumo médio humano de sal, nas regiões Leste e Sul do país, era de $15 \mathrm{~g}$ diários por pessoa, o que permitiria a ingestão diária de $30 \mathrm{mg}$ de base de cloroquina. No norte do país, o consumo médio de sal era maior, aproximadamente $22 \mathrm{~g}$ diários, por pessoa. Ali, considerava Pinotti, a concentração ideal de droga no sal seria $0,23 \%$ de difosfato de cloroquina, ou seja, $0,14 \%$ de base de cloroquina (Pinotti, 1957, p.22).

Para Pinotti, a utilização da base de cloroquina no lugar do difosfato de cloroquina tornaria o antimalárico mais barato. O método deveria ser aplicado em localidades que tivessem, em média, dez mil habitantes. Para abastecer de sal cloroquinado regiões com populações com mais de vinte mil habitantes, seria necessário o emprego de um misturador mecânico.

A opção pela utilização da base de cloroquina misturada ao sal de cozinha gerou um debate internacional, com pesquisas registradas em correspondência entre Emilio Pampana, diretor da Divisão de Erradicação da Malária da OMS, Karl Koenig, conselheiro químico da Bayer, e Mario Pinotti, diretor do DNERu, tema abordado na próxima seção (Pinotti, 1957, p.24).

Nessa segunda fase da pesquisa, os trabalhos de campo se concentraram em áreas malarígenas ${ }^{12}$; a localidade de Engenheiro Dolabela, em Minas Gerais, foi escolhida como laboratório (Paulini, 2004). Na terceira fase, o sal cloroquinado devia ser testado, principalmente, em áreas de difícil acesso, onde a aplicação do DDT se tinha mostrado ineficaz.

Em 1952, dois anos depois de iniciadas as pesquisas com o sal cloroquinado, as provas químicas de laboratório, as observações em doentes hospitalizados e os trabalhos de campo demonstraram a eficácia do método. No ano seguinte publicou-se uma nota prévia sobre o assunto ${ }^{13}$, após as provas de campo confirmarem os resultados positivos obtidos preliminarmente em condições experimentais. 
O método Pinotti teve expressiva repercussão no cenário internacional, em que se debatia a possibilidade de erradicação da malária. Especialistas e dirigentes de instituições de saúde mundo afora solicitavam esclarecimentos e detalhes das pesquisas realizadas pelos brasileiros. Considerado uma possível alternativa para superar as restrições técnicas e operacionais ao uso do DDT, o método poderia viabilizar, primeiro, o controle e, depois, a erradicação da malária, preconizada pela OMS a partir de 1955.

\section{O método Pinotti sob o escrutínio da saúde internacional}

Entre 19 e 25 de outubro de 1952, realizou-se em Belo Horizonte, capital de Minas Gerais, o $10^{\circ}$ Congresso Brasileiro de Higiene. No evento, o renomado malariologista venezuelano Arnaldo Gabaldón, da Divisão de Malária de seu país e membro do Panel of Experts on Malaria, da OMS, demonstrou grande otimismo quanto ao novo método brasileiro. Segundo Gabaldón (1952), a contribuição dos sanitaristas brasileiros, em especial Mario Pinotti, era imprescindível para a luta contra a doença. O sal cloroquinado estaria presente nas áreas em que não fosse possível a utilização do DDT.

No mesmo evento, Carlos Alberto Alvarado, malariologista argentino, professor de Higiene da Universidade de Tucumán e chefe do Coordination Office for Malaria Eradication Programmes (Comep), da Repartição Sanitária Pan-americana, também expressou seu entusiasmo quanto às perspectivas de o sal cloroquinado tornar-se nova arma contra a malária:

Mais uma vez o gênio do homem encontra a solução. Para aumentar a dívida do mundo com o Brasil, mais uma vez um brasileiro apresenta a brilhante ideia de como resolver o problema. Mario Pinotti pensa que essas pequenas doses de cloroquina podem misturar-se com sal, cloreto de sódio que todos nós consumimos. Feitos os testes químicos, farmacológicos e clínicos, concluiu que a estabilidade é completa e que a tolerância à droga é perfeita. Os primeiros resultados dessa intuição magnífica indicam a sua eficácia inquestionável. Assim estaria descoberto o processo para dominar a malária, quando os maravilhosos inseticidas residuais falharam (Alvarado, 1952, p.304). ${ }^{14}$

Em 1953, Arnaldo Gabaldón escreveu a Mario Pinotti reforçando suas expectativas em relação ao método brasileiro: "Estou muito preocupado com o problema da falta de bons povoados para testar a eficácia do sal cloroquinado. Você precisa fazer todos os esforços para tentar provar a inegável eficácia dessa droga ... Continuo a acreditar que você deu uma contribuição importante para o controle da malária, com a introdução do sal cloroquinado. Pretendemos usar esse método no segundo semestre deste ano, em grande área nossa" (Gabaldón, 6 mar. 1953). ${ }^{15}$ A grande preocupação de Gabaldón era reunir evidências de que o método proposto por Pinotti poderia ser uma estratégia complementar ao uso do DDT para viabilizar a meta de erradicação da malária preconizada pela OMS, que, na Venezuela, estaria sendo alcançada em algumas regiões. ${ }^{16} \mathrm{Um}$ dos aspectos que apontava como particularmente positivo era o baixo custo do método, o que favoreceria sua eficácia no controle inicial da doença e conduziria ao objetivo final da erradicação.

A apresentação do método do sal cloroquinado, por ocasião do 5 Congresso Internacional de Medicina Tropical e Malária, reunido em Istambul de 28 de agosto a 4 de setembro de 1953, foi fundamental para a repercussão internacional que o tema alcançaria 
na década de 1950 (Hochman, 2008). Ao comentar a comunicação de Pinotti nesse evento, Gabaldón (1953, p.250) destacou:

\begin{abstract}
Com referência ao uso da cloroquina misturada ao sal de cozinha comum, quero cumprimentar o Dr. Pinotti por ter introduzido um método que, acredito, possibilita pela primeira vez a aplicação de medicamentos para controle da malária na vida civil. A experiência da maioria dos países havia demonstrado ser possível controlar a malária com algumas das novas drogas, mas o custo de distribuição e supervisão torna proibitivo seu uso. O método do Dr. Pinotti resolve o problema do custo baixo e espero que venha a ser bastante empregado como ação complementar, quando necessário, nas campanhas de âmbito nacional cujo objetivo seja a erradicação da doença. ${ }^{17}$
\end{abstract}

Em 1957 Arnaldo Gabaldón se mostraria motivado a utilizar o método do sal cloroquinado no sul da Venezuela, onde o DDT estava falhando no objetivo da erradicação, provavelmente devido à transmissão extradomiciliária da malária pelo Anopheles darlingi, principal vetor na região (Gabaldón, 17 jun. 1957). No Brasil, contudo, a luta contra a malária e o uso do método Pinotti como parte dela não eram vistos, naquele momento, sob a perspectiva da erradicação. Segundo os malariologistas brasileiros, o sal cloroquinado deveria ser utilizado, em complemento ao DDT, com o objetivo de controlar a doença. ${ }^{18}$

O assunto foi veiculado pela imprensa. O jornal A Notícia, de 3 de setembro de 1953, estampou, em manchete: "Alcança repercussão mundial o método brasileiro de combate à malária". O título destacava a dimensão nacional, e o subtítulo ressaltava a singularidade da 'descoberta', associando-a às peculiaridades da região à qual o método se reportava de modo especial: "Nasceu a ideia das asperezas da luta antipalúdica na região amazônica Comunicação aos mais adiantados centros de pesquisas do mundo - Aplausos do Congresso Internacional de Doenças Tropicais ora reunidos em Istambul".

Nesse contexto, mais do que um novo método de combate à malária, o sal cloroquinado era enaltecido como algo que coroava uma tradição no país, a da malariologia e dos malariologistas. O sal cloroquinado foi apresentado em A Notícia como símbolo da "brilhante capacidade" dos cientistas brasileiros. A malária era referida como um grave problema de saúde pública que estava sendo vencido por esforços, inteligência e competência dos malariologistas do SNM. Mario Pinotti era reverenciado como personagem central dessa 'conquista':

A malária deixou de ser um problema ... Os fatos vieram confirmar o ponto de vista sustentado pela medicina brasileira através do Dr. Mario Pinotti. Quando se deu início à grande batalha contra a malária, eram registrados cerca de oito milhões de casos por ano, nas regiões afetadas. Hoje as estatísticas rigorosamente elaboradas pelo SNM acusam um índice de apenas 143 mil casos em todo território nacional. Só no Distrito Federal tínhamos cerca de 14 mil casos e hoje, depois de intensas pesquisas, foi possível localizar 3 casos. Isso quer dizer, simplesmente, que a malária deixou de existir no Brasil como problema. Uma área de 6.620.974 quilômetros quadrados foi e está sendo constantemente cuidada pelo SNM, que passou assim do combate direto à endemia, à fase de prevenção (Novas descobertas..., 2 dez. 1953).

O malariologista venezuelano Arnaldo Gabaldón, como vimos, foi um dos primeiros a reconhecer e divulgar a importância do trabalho de Mario Pinotti. A divulgação do método 
Pinotti no contexto internacional da saúde pública serviu para o fortalecimento do grupo de malariologistas associado ao SNM. Na quinta sessão do Expert Commitee on Malaria ${ }^{19}$ da OMS, reunido em Istambul de 7 a 12 setembro de 1953, foi apresentada mais uma comunicação sobre o método do sal cloroquinado, que despertou também grande interesse entre os presentes. Ao tratar do papel que as novas drogas sintéticas poderiam desempenhar no controle da malária, o relatório do comitê indicava: "Quando uma comunidade está vivendo sob condições que impedem totalmente a aplicação de medidas antimosquitos, o uso de drogas antimaláricas pode ser o único método viável de controle da doença. Um método engenhoso de distribuição, no qual a droga é misturada com sal de cozinha, em uma região onde este é escasso, tem sido aplicado sob controle governamental" (Pinotti, 1957, p.47) ${ }^{20}$

Na Conferência Internacional de Malária Para as Regiões Europeias e Leste do Mediterrâneo, promovida pela OMS em Atenas, em junho de 1954, Fernando Machado de Bustamante, delegado observador do Brasil e malariologista do SNM fortemente associado a Pinotti, chamou a atenção do plenário para a importância do sal cloroquinado em campanhas de controle da doença. Destacou que ele seria apropriado em circunstâncias não raras - em que os inseticidas não pudessem ser usados, como nas localidades com dificuldades de acesso e em regiões de baixa densidade demográfica, onde a aplicação domiciliária de inseticidas seria medida muito dispendiosa (Bustamante, 1954).

Em outubro de 1954 Pinotti recebeu correspondência de C.W.F. Winckel (7 out. 1954), então malariologista consultor do Hospital Mental de Amsterdã, cujo tema principal era uma reportagem do Journal of the American Medical Association, de 4 de setembro de 1954, que apresentava o método do sal cloroquinado como uma contribuição importante no controle da malária. ${ }^{21}$ Winckel tomara conhecimento das primeiras experiências e pedia mais informações ao diretor do SNM. A publicação da reportagem aconteceu no momento em que especialistas de malária da OMS reuniam-se para traçar novas rotas de combate à doença no mundo. Assim como o DDT, o sal cloroquinado foi planejado, a princípio, como método de controle. Quando teve início a campanha de erradicação global da malária da OMS, em 1955, e as dificuldades da empreitada tornaram-se conhecidas, as propostas que se apresentavam como inovadoras ganharam espaço. Foi em tal cenário que o método Pinotti, ainda que concebido para o contexto brasileiro, encontrou ambiente internacional propício para a sua difusão como alternativa viável - mas sujeito também a desconfianças e críticas.

Em carta dirigida a Fernando Bustamante, de 17 de fevereiro de 1956, Gabaldón relatava que o método do sal cloroquinado desenvolvido por Mario Pinotti teria uma agenda especial de discussão na $6^{a}$ Sessão do Comitê de Especialistas sobre Malária ${ }^{22}$ que aconteceria na Grécia, de 29 a 31 de junho do mesmo ano. O interesse pelo método vinha acompanhado da proeminência de seu idealizador, como se percebe no relato de Gabaldón sobre a movimentação em prol da concessão de um prêmio internacional a Pinotti. Nas palavras do malariologista da OMS, de 21 a 29 junho 1956, há dois pontos que são de interesse para o Brasil, como você pode 
ver na agenda provisória da reunião que provavelmente chegou ao Serviço Nacional de Malária.

O primeiro ponto é o intitulado "Ação contra o parasita da malária: drogas, Método de Pinotti, Sal de cozinha medicado". Fui convidado a participar da dita sessão e gostaria de apresentar à Comissão um informe detalhado de tudo o que vocês têm conseguido nesse domínio. Faça-me o favor de preparar o informe de modo que ele possa servir de texto para ser incluído no próximo Informe que o Comitê apresentará.

O outro problema, que lhe comunico confidencialmente, é que, em resposta à consulta sobre candidatos ao Prêmio Darling que fez o Director-Geral da Organização Mundial da Saúde Malária aos membros do Painel de Malária, propus o nosso Mario Pinotti como candidato. Acho que a apresentação da bibliografia sobre o Sal Cloroquinado e o relatório a que me referi anteriormente são elementos úteis para respaldar a candidatura que apresentei. Eu lhe agradeceria se me preparasse também a referida bibliografia e, se possível, me enviasse separatas das respectivas publicações, as quais eu levaria a Genebra ... (Gabaldón, 17 fev. 1956). ${ }^{23}$

Pinotti assumia uma crescente posição de destaque no campo da saúde pública internacional. Naquele momento, em 1956, como diretor do DNERu, contava com admiradores importantes. Gabaldón iniciou uma campanha para que o reconhecimento do método do sal cloroquinado coroasse também o trabalho do malariologista brasileiro. Na reunião em Atenas do Expert Committee on Malaria da OMS, discutiram-se aspectos relacionados ao emprego de drogas antimaláricas em campanhas de erradicação da doença e preparouse um relatório sobre o método do sal cloroquinado e sua utilização: "A Comissão tomou nota do método Pinotti, de administração em massa de cloroquina misturada com sal de mesa, que pode ser útil em algumas circunstâncias, e interessou-se em saber que a OMS está patrocinando uma série de experimentos controlados para testar a eficácia desse método na administração de drogas" (Pinotti, 1957, p.50). ${ }^{24}$ O Comitê também tratou do sal cloroquinado em publicações (Malaria Inform 1, WHO e Malaria Inform 15, WHO), nas quais divulgou os resultados dos trabalhos de Pinotti e Rostan Soares.

Na segunda reunião do Advisory Committe on Malaria da Repartição Sanitária Panamericana, em Maracay, Venezuela, de 26 a 29 de dezembro de 1956, Bustamante apresentou os resultados preliminares do emprego do sal cloroquinado na área de Engenheiro Dolabela. Fred L. Soper, diretor-geral daquela repartição, impressionou-se com os dados apresentados por Bustamante e declarou que aquele havia sido um dos mais importantes fatos levados àquela reunião (Bustamante, 1956). No ano seguinte, na 1ํㅡㄹ Reunião de Chefes de Serviços Nacionais de Malária dos Países da Bacia do Prata, realizada na Bolívia, Bustamante (1957) ressaltou:

nosso método profilático foi de novo reconhecido como arma valiosa nos programas de erradicação da malária, aprovou uma resolução baseada nos seguintes termos:

Que se mantenha o nome de "Método Pinotti" para a mistura de sal de cozinha com cloroquina, daraprim ou outra qualquer droga antimalárica.

Em vários países da América do Sul já se cogita do emprego do sal cloroquinado. O Dr. Fausto Fernandez, responsável pela campanha contra a malária no Peru, consultou-nos recentemente, sobre a aceitação do método pelo público, pois, desejoso de empregá-lo na região amazônica de seu país, manifestava temor de que o sal cloroquinado contivesse 
sabor amargo capaz de comprometer a sua boa aceitação. Mostramos-lhe o não fundamento de suas reservas e convidamo-lo a inspecionar as áreas em que estávamos usando o sal com cloroquina e verificar pessoalmente a sua perfeita aceitabilidade e a simplicidade de seu emprego na prática.

Em 1957 Emilio J. Pampana, malariologista italiano e chefe da Divisão de Malária da OMS, formalizou o interesse de sua organização no desenvolvimento do sal cloroquinado (Pampana, 8 mar. 1957). Pampana havia estabelecido contatos com Mario Pinotti pedindolhe mais esclarecimentos sobre o método. Solicitara também ao National Institutes of Health, do Public Health Service, dos EUA, a realização de investigações que comprovassem os resultados obtidos pelos malariologistas brasileiros: "Eu esperava poder enviar-lhe uma cópia do relatório do Dr. Coatney, que experimentou o método de sal cloroquinado em voluntários infectados com as cepas de Chesson vivax, mas parece que o relatório está atrasado, e pedi para lhe dizer, se ainda não sabe, que os resultados do doutor Coatney confirmam, como previmos, os resultados obtidos por você e por seus colegas de trabalho ...". ${ }^{25}$ Tais investigações foram confiadas a Robert Coatey, uma das maiores autoridades mundiais em drogas antimaláricas. O reconhecido pesquisador americano realizara seu trabalho junto a internos de prisões americanas e confirmou integralmente os resultados de Pinotti com o sal cloroquinado, mostrando, ainda, que resultados semelhantes poderiam ser obtidos com a associação do sal a um outro antimalárico, a pirimetamina. Coatey não havia publicado os resultados de suas pesquisas quando enviou uma correspondência a Mario Pinotti e Rostan Soares:

Há cerca de um ano a Organização Mundial da Saúde iniciou estudos experimentais em voluntários prisioneiros, para testar a eficácia supressiva da cloroquina e da pirimetamina quando adicionadas ao sal comum e em cepas Chesson da malária vivax induzidas por esporozoítos. ... Na realização desse experimento, os voluntários foram submetidos à dieta de sal cloroquinado por 10 e 13 dias, respectivamente, depois do surgimento do primeiro episódio infeccioso (primeira mordida) e entre 19 e 18 dias, respectivamente, após o surgimento do último episódio infeccioso (última mordida), cerca de uma semana depois. Cada um dos voluntários e o controle ou controles de cada episódio particular foi mordido por dez mosquitos fortemente infectados, como comprovado por dissecção pós-prandial. Os controles não receberam nenhuma droga e entraram na área de exames do hospital apenas para receber as picadas infectantes. A tabela abaixo apresenta os dados mais importantes e os resultados do experimento (Coatey, 29 maio 1957). ${ }^{26}$

Pinotti respondeu a Pampana em 11 de julho de 1957, detalhando o processo de preparação do sal cloroquinado. Forneceu informações sobre as condições de produção e armazenamento do método relacionado a peculiaridades locais, indicando a importância de fatores como umidade e temperatura. Demonstrava entusiasmo e valorizava o método como um possível instrumento de erradicação da malária até em áreas em que a campanha da OMS não tinha inicialmente intenção de atuar: "Sinto-me satisfeito com a sua opinião de que 'chegou o momento de utilizar o método no campo' e de que o novo método pode muito bem ser a solução para interromper a transmissão da malária em alguns países africanos ..." (Pinotti, 11 jul. 1957). ${ }^{27}$

Em 10 de outubro de 1957, Karl Koenig, conselheiro químico da Bayer, escreveu para Pampana. Manifestava ressalvas em relação ao mesmo e, cautelosamente, indicava possíveis 
falhas. Koenig não estava convencido dos resultados apresentados por Pinotti no $27^{\circ}$ Informativo da Malária, da OMS. Questionava também o modo como o malariologista brasileiro chegara a tal resultado. Solicitava que fossem fornecidas mais informações a respeito, para que o métdo pudesse ser totalmente aceito.

V.S. talvez se recorde da nossa conversação e correspondência a respeito do "Método Pinotti", da mistura de cloroquina com o sal de cozinha.

Meu amigo, Prof. Kikuth, de Düsseldorf, recentemente discutiu o assunto de novo comigo, tomando por base informações sobre Malária da OMS, que recebe com regularidade de seu escritório. O número em questão é: Mal/Inform/27 de 14 de agosto de 1957.

O referido amigo mostrou-me o boletim, e à página 6 nํำ há um parágrafo no sentido de que na preparação do sal cloroquinado, o difosfato de cloroquina pode ser substituído com vantagem pela cloroquina básica, pois que a droga deve ser mais barata em forma de base do que em forma de fosfato.

De acordo com os meus conhecimentos dos processos de fabricação, a preparação de cloroquina básica é consideravelmente mais onerosa que a de fosfato de cloroquina. Há ainda a acrescentar um outro ponto que, na minha opinião, é importante, qual seja, que a cloroquina básica é positivamente inferior com respeito à absorção através do trato digestivo, do que os sais solúveis de cloroquina, como o fosfato de cloroquina. Ademais, a cloroquina básica é, até certo ponto, sensível à luz. A superfície de cloroquina básica, que é um pó fino, adquire com facilidade uma coloração de cor marrom ao ser exposta à luz. Há ainda, que a cloroquina básica é praticamente insolúvel em água e o processo discriminado na Mal/Infor/27 pág.4, "Preparation of the solution", torna-se impossível com cloroquina básica.

Não será como Pinotti chegou às conclusões fornecidas na Mal/Inform/27 à pág.6. Entretanto, até que se obtenham outras informações do Pinotti, é preciso cautela ao recomendar o uso de cloroquina básica na preparação de sal cloroquinado (Koenig, 10 out. 1957).

Emilio Pampana, em correspondência enviada a Pinotti em 18 de maio de 1957, citou os dados que lhe foram enviados por Koenig. Apesar do interesse da OMS, havia dúvidas em relação a alguns aspectos técnicos relativos ao preparo e à utilização do sal cloroquinado. Pampana solicitava mais informações.

Conforme é de seu conhecimento reproduzimos as referidas instruções no idioma inglês e francês em nossa série de Mal/Inform (no 27), a qual circula por todas os membros ligados à Malária, da OMS. Acabo de receber uma carta do Dr. K. Koenig, a quem V.S. provavelmente conhece e que é um dos conselheiros médicos em químico terapêutica da Bayer, e estou enviando, anexo, uma cópia de sua carta de 10 de outubro de 1957, para sua informação. Estou certo que apreciará as observações do Dr. Koenig, porém gostaria imensamente de saber se o autor do memorandum que V.S. gentilmente me enviou pudesse nos remeter maiores detalhes sobre as possíveis desvantagens atribuídas pelo Dr. Koenig à mistura da base de cloroquina e sal (Pampana, 18 maio 1957)

O método do sal cloroquinado passava a ser considerado, por Pampana, um potencial complemento ao DDT ou uma alternativa em regiões onde a aplicação do inseticida era inviável. Cabe lembrar que, por esta última razão, a África foi excluída na campanha de erradicação liderada pela OMS (Cueto, 2007). 
Em 1957 Mario Pinotti procurou responder às questões sobre o modo de preparo do sal. Em 14 de novembro de 1957, uma nova carta de Pinotti foi enviada para Pampana. Em defesa de seu método, apresentou as publicações baseadas nas pesquisas realizadas por ele e sua equipe, que confirmavam o valor positivo do método.

Em resposta às considerações tecidas por Karl Koenig, conselheiro médico em química terapêutica da Bayer, sobre as restrições que faz quanto à substituição do difosfato de cloroquina pela cloroquina base, na mistura do "Sal Cloroquinado", que havíamos aconselhado com o intuito de tornar este método mais econômico, merecem todo o nosso acatamento, embora já estejamos verificando os detalhes apontados por esse técnico, para um juízo mais seguro sobre o assunto.

Contudo, queremos ressaltar aqui que todas as nossas pesquisas realizadas com o método do sal cloroquinado na profilaxia da malária foram efetuadas empregando-se sempre o difosfato de cloroquina (Aralen) como agente terapêutico. Essa preferência foi resultante da larga experiência que já possuíamos com esse medicamento nas campanhas que havíamos realizado. Aliás, esse detalhe já fora por nós abordado em diversas publicações ... (Pinotti, 14 nov. 1957).

Após listar os principais trabalhos sobre o método do sal cloroquinado, Pinotti retificava que todas as experiências de suas pesquisas haviam sido orientadas em torno do difosfato de cloroquina misturado ao sal. A substituição do difosfato de cloroquina pela cloroquina base, sugerida por Pinotti, visava baratear o produto e torná-lo mais viável como medida cotidiana da profilaxia antimalárica. Alertava que o trabalho de sua equipe ainda não fora concluído e por isso não poderia fornecer ainda os resultados detalhados de suas pesquisas.

Em 1958 Pinotti consolidava sua carreira política, com a chegada ao Ministério da Saúde. No ano seguinte, a Organização Pan-americana da Saúde (Opas) reconheceu oficialmente, em seus documentos, o sal cloroquinado como importante instrumento de combate à malária na região amazônica - instrumento este que poderia alavancar a campanha de erradicação da malária no Brasil (PAHO/WHO, 1959, 1960). Efetivamente, o programa do sal cloroquinado foi implementado entre 1959 e $1961^{28}$, no entanto já em 1960 o método, assim como seu idealizador começaram a sofrer mais críticas. Pinotti foi afastado do governo em agosto desse ano, num período de efervescência política devido às eleições presidenciais que ocorreriam em outubro. Sua gestão no Ministério da Saúde e o partido a qual era vinculado, o PSP, foram alvos de graves denúncias de corrupção. Inúmeras investigações ocorreram no mandato de Jânio Quadros e inquéritos, no governo militar, mas foram arquivados. Pinotti jamais retornou à vida pública depois de 1960 (Hochman, 2010, p.182).

Além das desconfianças de suas bases experimentais, o método Pinotti foi criticado em relação a sua eficácia e efeitos não previstos. Críticos contemporâneos do método, bem como aqueles que comentaram posteriormente a política de controle da malária no Brasil alegaram que o método Pinotti enfrentou muitas dificuldades em alcançar os resultados: nem todo o sal ingerido em áreas em que o método deveria ser aplicado foi cloroquinado; algumas das populações-alvo consumia pouco sal, exigindo assim maior quantidade de cloroquina; uma vez que o difosfato de cloroquina usado na mistura é altamente solúvel em água, em regiões muito úmidas como a Amazônica ocorreu uma diminuição da droga 
na associação com sal; as mulheres gestantes e os bebês em amamentação não consumiam o sal; crianças comiam pouco sal, e também rejeitavam o sal cloroquinado devido ao sabor. Alguns estudos sugerem que a resistência do parasita à cloroquina foi causado pela distribuição descontrolada de sal. A utilização do método foi criticada também por desconsiderar as realidades socioculturais das populações-alvo (Rachou, 1960; Payne, 1988; Moraes, 1990; Verdrager, 1995; Zalis, 2000; Spielman, 2006; Hochman, 2008, p.182-183; Hochman, 2010).

O compromisso firmado em 1958 entre o governo JK e a Agência de Cooperação Internacional estadunidense (ICA) para a conversão do programa brasileiro de controle em programa de erradicação não correspondeu de imediato às expectativas da OMS, que preconizava a imediata transformação dos programas de controle em programas de erradicação. Em discursos anteriores a esse período, Pinotti e Kubitschek apresentavam a malária como questão de saúde pública resolvida, fortalecendo os procedimentos de controle e o grupo de malariologistas resistentes à conversão imediata do programa brasileiro em uma campanha de erradicação (Programa..., 1955, passim). A adesão ao programa da OMS, já no final da década de 1950, poderia ser uma oportunidade para o governo federal obter auxílio financeiro e aplicá-lo em áreas como a saúde pública, que perdera recursos em benefício do cumprimento do Plano de Metas e da construção de Brasília, como também em virtude da crise financeira ocorrida em meados do mandato de Kubitschek (Silva, 1992; Vizentini, 2004). Por outro lado, a partir do segundo mandato de Eisenhower (1957-1961) a erradicação da malária - "a guerra à malária" - passou a integrar a política externa dos EUA, então no auge da Guerra Fria, condicionando mesmo o financiamento de ações antimaláricas (Cueto, 2008; Hochman, 2008).

A primeira sinalização de mudanças na política de saúde do governo JK para erradicação da malária foi a criação do Grupo de Trabalho de Erradicação e Controle da Malária (GTEM), em 1958, presidido pelo diretor-geral do DNERu, Mario Pinotti. Em discurso de inauguração do GTEM, Pinotti defendeu ações rápidas contra a doença. ${ }^{29}$ As armas apontadas por ele na luta pela erradicação seriam o DDT e o sal cloroquinado: o primeiro como ação direta contra o mosquito; o segundo, contra o parasito no sangue. O prazo estipulado para erradicação da doença seria de cinco anos, de acordo com as recomendações da OMS. No entanto, Pinotti afirmou que a meta só poderia ser cumprida se houvesse auxílio do governo norte-americano, representado pelo Ponto IV. ${ }^{30}$ Pelo prognóstico do presidente do GTEM, sem auxílio o Brasil só alcançaria a erradicação da malária em, no mínimo, sete anos (Noticiário, 1958, p.216). O governo brasileiro firmou convênios de cooperação com a Repartição Sanitária Pan-americana e com a International Cooperation Administration (ICA), do governo norte-americano (p.213).

Para Fernando Bustamante, coordenador do GTEM e um dos braços direitos de Pinotti, a campanha de erradicação da malária no território nacional não seria uma empreitada fácil. A região amazônica constituía um dos problemas que o programa de erradicação no Brasil enfrentaria. As condições epidemiológicas da região, relacionadas à biologia do vetor mais comum, o Anopheles darlingi, seriam os obstáculos iniciais. Os tipos de habitação, o modo de vida da população, os problemas administrativos decorrentes da extensão do território e da baixa densidade demográfica representariam também sérias ameaças à campanha. Mesmo em tal conjuntura, Bustamante foi um dos defensores da utilização do sal 
cloroquinado. Argumentava Bustamante que a eficácia do método estaria subjacentemente demonstrada em várias regiões do país, inclusive na região amazônica. Alegava também que praticamente todo o sal de cozinha consumido na Amazônia geográfica (estados e territórios federais de Rondônia, Acre, Rio Branco e Amapá) entrara pela foz do rio Amazonas, sendo distribuída por grandes importadores de Belém e Manaus.

De fato, havia certas facilidades para o controle do movimento do sal e para a sua mistura com o medicamento. A maior parte do produto foi importada com o sal grosso a granel e triturada ou moída em grandes armazéns de Belém ou Manaus, antes de ensacada para a venda no interior. A instalação de unidades para mistura do medicamento com o sal, antes de seu ensacamento nos armazéns referidos, constituiu a providência básica com que se tratou a maior parte do sal que entrou na região.

Embora certos problemas no emprego do método Pinotti pudessem impedir a proteção inicial de todos os habitantes, os malariologistas estavam convencidos de que o método era o melhor recurso profilático disponível para erradicar a malária na Amazônia brasileira. Na pior das hipóteses, acreditavam que o sal antimalárico controlaria inicialmente a transmissão na maior parte da área, de modo mais efetivo e mais econômico do que os inseticidas. Observações e estudos mais detalhados, feitos no decorrer do programa, indicariam as providências para solucionar problemas eventuais, a exemplo daqueles relacionados aos grupamentos indígenas que não consumiam sal na alimentação e outros de mesmo caráter (Bustamante, 1959).

Para Bustamante, o custo referente do sal cloroquinado seria relativamente alto, porque entre $30 \%$ e $40 \%$ do sal consumido destinavam-se à salga de peixes, carnes, couros, alimentação de gado etc., e não ao preparo de alimentos. Portanto, o sal para esta última finalidade teria um aumento nessa mesma faixa. Ainda assim, o custo do combate à malária pelo método Pinotti seria menor do que o dos programas baseados em ações de borrifamento de inseticidas. Bustamante levantou também questões relativas aos hábitos de consumo de sal da população da região amazônica. Para o coordenador do GTEM, exemplos de obstáculos ao método do sal cloroquinado seriam a carne salgada com sal grosso, inadequado para a utilização do medicamento, e o aumento de embalagens pequenas do sal refinado. Este último não seria um problema muito grave, já que a população que consumia esse produto era moradora das grandes cidades. Já a proibição da salga de carne com sal grosso poderia contribuir para melhorar a eficácia do método (Bustamante, 1959).

Em meados da década de 1960, já no governo militar, o programa nacional de malária que fora comandado por Pinotti foi criticado explicitamente. O Plano Nacional de Erradicação da Malária: operações para o quinquênio 1967-1971, publicado em 1966, continha críticas ao DNERu e ao Ministério da Saúde, por adotarem posturas centralizadoras e concentrarem os recursos financeiros destinados ao GTEM, em 1958. Ambas as instituições estiveram sob a direção de Mario Pinotti, responsável pela distribuição dos recursos que patrocinavam tanto ações de erradicação como práticas controle. O documento apontava também a ausência de verbas para transformar os programas de controle em programas de erradicação, e havia uma crítica específica ao método adotado para combater a malária. A utilização do sal cloroquinado na região Amazônica foi vista negativamente nesse relatório: "Infelizmente, o sal cloroquinado não respondeu ao que se esperava dele, dadas certas dificuldades 
técnicas e outros obstáculos referentes à sua distribuição. Posteriormente, o surgimento de fatores epidemiológicos ligados ao aparecimento de uma cepa de P. falciparum, tolerante ou resistente às ministrações usuais de cloroquina, completariam a contraindicação do método" (Brasil, 1966, p.34-35).

Mario Pinotti foi exonerado do cargo de ministro da Saúde no final do governo Juscelino Kubitschek. A queda do político feriu o sanitarista e comprometeu sua criação, e o sal cloroquinado deixou de fazer parte das ações de controle da malária no país. Assim encerraram-se quase dez anos de discussões sobre a inovação brasileira para controlar de vez e erradicar eventualmente a malária. No entanto, o método Pinotti foi reconhecido internacionalmente como um possível instrumento de combate à malária em áreas mais hostis à ocupação humana, e continuou a ser adotado fora do país mesmo após ter sido, junto com seu criador, banido do Brasil. Uma nota publicada em 1966, no Boletim da OMS, trazia informe sobre o uso do sal cloroquinado na Tanzânia, reconhecendo Mario Pinotti como inventor do método (Clyde, 1966). E no Vietnã, o uso do o sal cloroquinado começou após 1960, com reconhecimento da OMS.

O sal cloroquinado começou a ser duramente questionado no Brasil e abandonado, não por acaso, a partir do ocaso político de seu idealizador. Essa forte associação entre o método e Pinotti, se possibilitou a consagração quase instantânea do método e a ascensão política de seu criador, facilitou seu abandono logo após a queda de Pinotti. Em menos de uma década, o "método Pinotti" foi formulado e testado, celebrado como uma inovação brasileira, obteve reconhecimento internacional, integrou as estratégias nacionais de luta contra a malária, foi considerado, pelas agências da saúde internacional, integrante do Programa Global de Erradicação da Malária, foi criticado e rapidamente desapareceu da política de saúde brasileira, ainda que tenha sido testado em países da Ásia, África e América do Sul até meados de 1960.

\section{Considerações finais}

O novo método de tratamento da malária produzido pelos malariologistas brasileiros despertou interesse da comunidade internacional de saúde pública. A correspondência trocada entre os pesquisadores brasileiros que trabalhavam com o método e os especialistas em malária da OMS evidencia uma tensão quanto ao esclarecimento total do procedimento. Mario Pinotti, à frente das pesquisas, demonstrava confiança constante em relação ao método, acreditando que ele seria a arma definitiva ou um 'golpe final' aplicado na luta contra a malária. Esse 'golpe imediato' era entendido pelos malariologistas da OMS como uma ação que visava à erradicação e devia ser processada o mais rápido possível. No cenário nacional, os sanitaristas brasileiros incluíram o método Pinotti como mais um instrumento de controle da malária. Nesse contexto, os progressos alcançados com o uso do DDT, na primeira metade de década de 1950, e o surgimento do sal cloroquinado justificavam parte do otimismo dos malariologistas; no caso brasileiro, havia a crença de que a malária seria uma questão de saúde pública quase superada no país.

O reconhecimento do trabalho de sanitarista e sua atuação no SNM, DNERu e Ministério da Saúde fizeram de Pinotti quase uma unanimidade, e seu nome foi dado ao método do 
sal cloroquinado, que se pretendia ser a contribuição brasileira à malariologia mundial. $\mathrm{O}$ discurso de Mario Pinotti informando a gravidade da malária no Brasil, em 1958, almejava transmitir confiança e seriedade na proposta do governo brasileiro para a erradicação da malária. O auxílio financeiro para campanha, solicitado por Pinotti, seria atendido em virtude do reconhecimento de seu trabalho como sanitarista, mas também porque o governo brasileiro não tinha alternativa, dado que a "guerra contra a malária" do governo dos EUA - e o financiamento nela embutido e dirigido para a erradicação - era parte do esforço de contenção do comunismo em um ambiente de Guerra fria. Pinotti representava a principal autoridade de malária no Brasil.

A trajetória de Mario Pinotti e de seu método é exemplar na saúde pública do período que se inicia com a Segunda Guerra Mundial, marcado pela crença na necessidade de ações estatais coordenadas e verticais em nível nacional, pelo 'otimismo sanitário e terapêutico', caracterizado pela confiança de que as novas drogas e inseticidas levariam à 'conquista' das doenças infectocontagiosas, e pela compreensão de que a doença era um obstáculo ao desenvolvimento. Essa trajetória esteve fortemente associada ao programas de desenvolvimento dos anos 1950, que visavam superar as endemias rurais, recuperando, assim, a população do interior do Brasil para o trabalho rural e incorporando as áreas afetadas aos projetos de modernização da agricultura.

O método foi testado, aceito e celebrado enquanto Pinotti esteve no comando da saúde pública brasileira. No ambiente da saúde internacional, o sal cloroquinado foi reconhecido pela OMS - ainda que várias dúvidas pairassem sobre os estudos que lhe deram origem - $\mathrm{e}$ sobreviveu alguns anos ao ocaso do sanitarista brasileiro. A crítica e a rejeição ao método, no Brasil, ocorreram imediatamente após o afastamento político do seu criador. No Brasil, a resistência a Pinotti parece ter sido mais importante para o abandono do método que leva seu nome do que o argumento de que ele produzia resistência do plasmódio à cloroquina.

\section{AGRADECIMENTOS}

Este artigo é resultado de projetos de pesquisa que contaram com apoio de bolsas da Capes e do CNPq e financiamento do Observatório História e Saúde, da Casa de Oswaldo Cruz/Fiocruz (Rede Observatório de Recursos Humanos em Saúde, MS/OPAS). Agradecemos as sugestões e críticas dos pareceristas anônimos e de Simone Petraglia Kropf.

\section{NOTAS}

${ }^{1}$ A Itália possuía renomada tradição de pesquisas e ações sanitárias contra a malária, que era endêmica no país (Snowden, 2006).

${ }^{2}$ O SNM se tornaria o mais forte dos 12 serviços nacionais criados entre 1941 e 1942.

${ }^{3}$ Pinotti foi ministro da Saúde pela primeira vez de junho a setembro de 1954, no segundo governo de Getúlio Vargas, tendo deixado o ministério logo após o suicídio do presidente.

${ }^{4}$ Em estudo de 1955, Rostan Soares reconhece os resultados da utilização intensa do DDT nos cinco anos após sua descoberta. A introdução desse trabalho seria a preparação do terreno para colocar em discussão o novo método pesquisado. O sal cloroquinado surgia como complemento à principal ação de combate à malária, o DDT (Soares, 1955).

${ }^{5}$ Em 1929 foi criada The Darling Foundation, em homenagem à memória do doutor S.T. Darling. A partir de 1932, a Fundação passou a premiar malariologistas que se destacavam no controle e combate 
da malária. Nomes importantes da agenda internacional da malária ganharam a premiação na década de 1950, como G. Robert Coatney (1954), P.F. Russell (1957) e E.J. Pampana (1959) (WHO, s.d.).

${ }^{6}$ Nas primeiras linhas do seu Programa de Saúde Pública, o médico e candidato à Presidência Juscelino Kubitschek estabeleceu a associação entre saúde e desenvolvimento: as doenças seriam, em parte, responsáveis pela pobreza e atraso das nações subdesenvolvidas. Juscelino afirmava que, após a Segunda Guerra Mundial, a saúde tornou-se não apenas uma questão nacional, mas também internacional, afligindo tanto os países mais pobres como os mais ricos. Deixava transparecer, em seu programa, uma enorme dose de otimismo em relação à solução dos problemas médico-sanitários, e a crença no aperfeiçoamento e desenvolvimento da medicina depois da Segunda Guerra Mundial (Programa..., 1955).

${ }^{7}$ Aludimos ao título do livro de Paul Russel (1955), um dos principais malariologistas norte-americanos, da Fundação Rockefeller.

${ }^{8}$ Rachel Carson publicou, em 1962, o livro Primavera silenciosa, em que analisa os efeitos devastadores produzidos por duas décadas de utilização do DDT. Segundo a autora, a substância penetra na cadeia alimentar e se acumula nos tecidos gordurosos dos animais e do homem (chegou a ser detectada presença de DDT até no leite humano), com risco de causar câncer e dano genético (Carson, 1969; ver também Dunlap, 2002).

${ }^{9}$ O trabalho de Soares (1955) tinha por objetivo colocar em discussão o novo método pesquisado. O sal cloroquinado surgia como alternativa à principal ação de combate à malária, o DDT (Soares, 1955).

${ }^{10}$ O termo 'supressivo' era empregado com o sentido de preventivo clínico, isto é, medicamento que, embora não impeça a infecção malárica, é capaz de evitar a manifestação de seus sintomas clínicos, por manter a parasitemia em nível muito baixo (Deane et al., 1953).

${ }^{11}$ Avaliando o sal de cozinha como veículo de medicamentos antimaláricos e acreditando no sucesso desse método brasileiro de profilaxia da doença, Pinotti registrou em algumas publicações os avanços de suas pesquisas (Pinotti, 1957; Pinotti, Soares, 1956).

${ }^{12}$ Em dezembro de 1953, o jornal A Notícia anunciava as pesquisas dos cientistas brasileiros e apresentava o sal cloroquinado como método revolucionário. A reportagem informava que os consumidores de sal não distinguiriam o sal de cozinha e o sal misturado à cloroquina, que não apresentava gosto, cheiro ou sabor (Novas descobertas..., 2 dez. 1953).

${ }^{13}$ Rostan Soares e Mario Pinotti comunicaram os primeiros resultados das pesquisas em 1953, no $11^{\circ}$ Congresso Brasileiro de Higiene, em Curitiba. O trabalho descrevia o funcionamento do novo método, as áreas nas quais ele seria utilizado e suas justificativas de uso (Soares, Pinotti, 1953).

14 “Pero aqui outra vez el gênio del hombre encuantra la solución. Y para aumentar la divida del mundo con el Brasil, es otra vez brasileiro el que tiene la idea genial de como resolver el problema. Mario Pinotti piensa que estas pequenas dosis de cloroquina pueden mesclarse con la sal, el cloruro de sódio que todos debemos consumir. Nace las pruebas quimicas, farmacológicas y clínicas y encuentra que la estabilidad es completa; que, la tolerancia a la droga es perfecta, y los primeiros resultados de esta intuición magnifica indican su incuestionable eficácia. Estaria asi descubierto el procedimiento para dominar la malaria donde fallaram los maravilhosos insecticidas de acción residual". Nesta e nas demais citações de textos em outros idiomas, a tradução é livre.

15 "Estoy muy preocupado con el problema de la carencia de pueblos buenos para probar la eficacia de la sal cloroquinada. Es necesario hacer todos los esfuerzos posibles para probar de manera indiscutible y abundante la eficacia de esa droga ... Continuo creyendo que Usted ha hecho una gran contribución a la lucha antimalarica con la introducción de la sal cloroquinado. Estamos proyectando emplear este método en el segundo semestre del presente año en una amplia zona nuestra".

${ }^{16}$ Sobre a atuação de Gabaldón na campanha de erradicação da malária na Venezuela, ver Gutierrez, 1988.

17 "With reference to the use of chloroquine mixed with common cooking salt, I want to congratulate Dr. Pinotti for having introduced a method which, I believe, makes possible for the first time the application of drugs for malaria control in civilian life. Experience of most countries have shown that it was possible to control malaria with some of the new drugs, but the cost of distribution and supervision makes prohibitive the use of such drugs. Dr. Pinotti's method solves the problem of light cost and therefore I hope it will be used at length as a complementary action where necessary in the nationwide campaigns which have as their objective the eradication of the disease".

${ }^{18}$ A compreensão do conceito de erradicação foi imprescindível para o desenvolvimento de programas que objetivavam acabar com a malária. Segundo Rita B. Barata (1998), o conceito de erradicação da 
doença foi proposto no $4^{\circ}$ Congresso Internacional de Medicina Tropical e Malária, em 1948. Esse conceito seria resultado da experiência adquirida nos programas de controle na Grécia, na Venezuela e nos EUA. A tentativa de erradicar a A. labranchiae na região da Sardenha não teve êxito. O programa mudou de estratégia centrando-se não mais no vetor, mas sim no parasita. A nova tática consistia no combate intenso aos anofelinos infectantes, erradicando-se o parasita na população. A distinção entre controle e erradicação foi estabelecida pelo Comitê de Peritos em Malária da OMS em 1955. Segundo o Comitê, nas ações de controle o objetivo era reduzir a transmissão a um grau suportável, ao passo que na erradicação almejava-se o extermínio da doença (Barata, 1998; Brown, 1998; Brasil, 1966).

${ }^{19}$ O Comitê era constituído pelos seguintes membros: doutor M.K. Afridi (Paquistão); Sir Gordon Covell (Inglaterra); doutor Mario Pinotti (Brasil); doutor S. Rajendram (Ceilão); doutor Paul F. Russell (Fundação Rockefeller); doutor M.A. Vaucel (França); doutor I.H. Vincke (Congo Belga). Consultores: professores G.A. Livadas (Grécia) e G. Mac Donald (Inglaterra). Secretários: doutores E.J. Pampana e M.A. Farid, ambos da OMS.

20 "Where a comunity is living under conditions which totally preclude the application of antimosquito measures, the use of antimalarial drugs may be the only practicable method of controlling the disease. An ingenious method of distribution by singling the drug with table salt has been used in an area where the latter commodity is scarces and is issued under government control".

${ }^{21}$ Winckel refere-se à matéria "Brazil: Antimalarian Campain" (Brazil..., 4 set. 1954).

${ }^{22}$ Este Comitê era constituído pelos seguintes membros: doutor M.K. Afridi (Paquistão); S.J. Bruce Chawtt (Nigéria); A. Gabaldón (Venezuela); L.F. Gunaratina (Ceilão); K.C. Liang (China); L. Livadas (Grécia); G. Mac Donald (Inglaterra); L. Raffaele (Itália); e J. Singh (Índia). Consultores: Sir Gordon Covell (Inglaterra); M.E. Farinaud (França); e P.E. Russell (Fundação Rockefeller, EUA).

${ }^{23}$ En la VI Sesión del Comité de Expertos Sobre Malaria que se reunirá en Atenas del 21 al 29 de Junio de 1956 hay dos pontos que son de interés para el Brasil, como Usted podra ver en la Agenda Provisional de dicha Sesión que seguramente ha llegado al Servicio Nacional de Malaria. //El primer punto es el titulado "Medidas contra los parásitos malarios: drogas, Método de Pinotti, Sal de cocina medicamentosa". Yo estoy invitado para asistir a dicha Sesión y me gustaría presentar a consideración del Comité un Informe detallado de todo lo que Ustedes hayan conseguido en este campo. Yo le ruego que me haga el favor de hacer preparar dicho informe en forma que pueda servir de texto para ser incluido en el Informe que presentará el Comité. //El otro problema, que de modo confidencial le comunico, es que como respuesta a la consulta sobre candidatos al Premio Darling que hiciera el Director General de la Organización Mundial de la Salud a los miembros del Panel de Malaria yo propuse a nuestro Mario Pinotti como candidato. Creo que la presentación de la bibliografía referente a Sal Cloroquinada más el informe a que hice referencia anteriormente sean elementos útiles para respaldar la candidatura que presente. Yo le agradecería me hiciera preparar también dicha bibliografía, y si es posible me enviara separatas de las publicaciones respectivas, las cuales llevaría yo a Ginebra ..."

24 "The Committee took note of Pinotti's method of mass administration of chloroquine mixed with table salt, which might be of value in some circumstances, and was interested to learn that WHO is sponsoring a series of controlled experiments to test the efficacy of this for administration of drugs".

25 "I hoped to be able to send you a copy of the report of Dr. Coatney, who experimented with your method of chloroquine salt on volunteers infected with the Chesson vivax strains: but the report seems to suffer from some delay, and I wanted to tell you, if you do not yet know it, that Dr. Coatney's results confirm, as we foresaw, the results of yourself and your co-workers ...". Pampana mostrou-se também preocupado porque a Wyeth International, indústria farmacêutica norte-americana, havia patenteado o sal cloroquinado ou pirimetaminizado, e uma vez que o produto fosse preparado comercialmente, o custo do tratamento poderia encarecer (Pampana, 8 mar. 1957). A Wyeth instalou uma filial no Brasil em 19 de outubro de 1949, graças a uma associação da matriz, na Filadélfia, com o Instituto Medicamenta Fontoura. Ela era, então, a principal fornecedora de penicilina para o Instituto. A parceria foi responsável, em 1954, pela criação da primeira fábrica sul-americana de penicilina, em São Bernardo do Campo, no ABC paulista. Com a tecnologia do centro de pesquisas da Filadélfia, as Indústrias Farmacêuticas Fontoura-Wyeth tornaram-se líder na produção e comercialização de antibióticos (Wyeth, s.d.).

26 "About a year ago at the request of the WHO we inaugurated experimental studies in prisoner volunteers to test the suppressive efficacy of chloroquine and pyrimethamine when added to common salt and against sporozoite-induced Chesson strain of vivax malaria. ... In carrying out the actual test, the volunteers were subjected to the drug-salt diet for 10 and 13 days respectively after the first biting (infection) episode and for 19 and 18 days respectively after the last biting (infection) episode approximately 
one week apart. Each of the test subjects and the control or controls for a particular episode was bitten by 10 heavily infected mosquitoes as proved by post-prandial dissection. The controls received no drug and entered the test area of the hospital only for the purpose of receiving infective bites. Relevant data and the results of the test are given in the table below".

27 "I feel pleased about your opinion that 'the time has come to utilize the method in the field' and that the new method may well be the solution for interrupting malaria transmission in certain African countries..." ${ }^{28}$ Há referências de que o sal cloroquinado foi utilizado em empreendimentos privados, como em áreas de exploração do manganês no Amapá (Drummond, Pereira, 2007).

${ }^{29}$ Há uma mudança radical de opinião no discurso de Pinotti em relação a malária em 1958. A doença passa a ser vista pelo diretor do DNERu como grave questão de saúde pública, a ser erradicada. Lembremonos de que em 1955 Pinotti e Kubitschek apresentaram a malária como uma doença controlada, em vias de desaparecer (Programa..., 1955).

30 O Ponto IV seria uma expansão do Plano Marshall, programa de recuperação dos países europeus, depois da Segunda Guerra Mundial. Foi criado em 1949 pelos EUA, para incentivar o desenvolvimento de nações e bloquear a expansão comunista liderada pela URSS.

\section{REFERÊNCIAS}

ALVARADO, Carlos A.

Progressos de la lucha atimalarica en el continente. Revista Brasileira de Malariologia e Doenças Tropicais, Rio de Janeiro, v.4, n.4, p.299-306. 1952.

BARATA, Rita Barradas.

Malária e seu controle. São Paulo: Editora Hucitec. 1998.

BRASIL.

Ministério da Saúde. Plano Nacional de Erradicação da Malária 1966: operações para qüinqüênio 1967-1971. Brasília: Ministério da Saúde. 1966.

\section{BRAZIL...}

Brazil: Antimalarian Campain. Journal of the American Medical Association, Chicago, v.156, n.1, p.64-65. Disponível em: http://jama.amaassn.org/content/156/1.toc. Acesso em: 19 abr. 2011.

BROWN, P.J.

Failure-as-success: multiple meanings of eradication in the Rockefeller Foundation Sardinia project, 1946-1951. Parassitologia, Roma, v.40, n.1-2, p.117-130. 1998.

BUSTAMANTE, Fernando Machado.

Considerações sobre certos problemas especiais relacionados com a erradicação da malária no Brasil. Revista Brasileira de Malariologia e Doenças Tropicais, Rio de Janeiro, v.11, n.1, p.15-16. 1959.

BUSTAMANTE, Fernando Machado. Estado atual do problema da malária. Revista Brasileira de Malariologia e Doenças Tropicais, Rio de Janeiro, v.10, n.1, p.79-99. 1958.

BUSTAMANTE, Fernando Machado. Resistência do comportamento do Anopheles darlingi. Trabalho apresentado na 1. Reunião de Chefes de Serviços Nacionais de Malária dos Países da Bacia da Prata, 3-9 fev. 1957, Cochabamba. Fundo Rostan Soares, doc.RE/PI/ RJ 9002040/3. (Casa de Oswaldo Cruz, Fundação Oswaldo Cruz). 1957.

BUSTAMANTE, Fernando Machado. Comunicação oral. Apresentada na 2. Reunião do Advisory Committe on Malaria, da Repartição Sanitária Pan-americana, 26-29 dez. 1956, Maracay. Fundo Rostan Soares, doc.RE/PI/RJ 9002040/3. (Casa de Oswaldo Cruz, Fundação Oswaldo Cruz). 1956.

BUSTAMANTE, Fernando Machado.

Comunicação oral. Apresentada na Conferência Internacional de Malária para as Regiões Européias e Leste do Mediterrâneo, jun. 1954, Atenas. Fundo Rostan Soares, doc.RE/PI/RJ 9002040/3. (Casa de Oswaldo Cruz, Fundação Oswaldo Cruz). 1954.

CAMARGO, Erney Plessmann.

A malária encenada no grande teatro social. Revista do Instituto de Estudos Avançados da USP, São Paulo, v.9, n.24, p.1-28. 1995.

CARSON, Rachel.

Primavera silenciosa. São Paulo: Melhoramentos. 1969.

\section{CLYDE, D.F}

Suppression of malaria in Tanzania with the use of medicated salt. Bulletin of the World Health Organization, Geneva, v.35, n.6, p.962-968. 1966.

COATEY, Robert.

Carta a Rostan Soares. S.l. Fundo Rostan Soares; doc.RS/DT/SC 19520640. (Casa de Oswaldo Cruz, Fundação Oswaldo Cruz). 29 maio 1957. 
CPDOC.

Centro de Pesquisa e Documentação de História Contemporânea do Brasil. Base de Dados do acervo do CPDOC. Mario Pinotti [verbete]. Diponível em: http://www.fgv.br/ CPDOC/BUSCA/Busca/BuscaConsultar.aspx. Acesso em: fev. 2010. s.d.

\section{CUETO, Marcos.}

International health, the early cold war and Latin America. Canadian Bulletin of Medical History/ Bulletin Canadien d'Histoire de la Médecine, Thunder Bay, v.25, n.1, p.17-41. 2008.

CUETO, Marcos.

Cold War, deadly fevers: malaria eradication in Mexico, 1955-1975. Washington: Woodrow Wilson Center Press. 2007.

DEANE, L.M. et al.

Experiência de campo, realizada na Amazônia, sôbre o valor supressivo do camoquin na Malária. In: Congresso Brasileiro de Higiene, 10., 1953, Belo Horizonte. Anais... S.l.: s.n. p.338-453. 1953.

DRUMMOND, José A.; PEREIRA; Mariângela de A.P.

O Amapá nos tempos do manganês: um estudo sobre o desenvolvimento de um estado amazônico, 1943-2000. Rio de Janeiro: Garamond. 2007.

DUNLAP, Thomas R.

DDT: scientists, citizens, and public policy.

Princeton: Princeton University Press. 1981.

FARID, M.A.

Relatório do primeiro curso de erradicação da malária para pessoal de nível profissional do Brasil. Brasília: DNERu/Ministério da Saúde. 1968.

FONSECA, Cristina.

Saúde no governo Vargas (1930-1945): dualidade institucional de um bem público. Rio de Janeiro: Editora Fiocruz. 2007.

GABALDÓN, Arnoldo. Carta a Fernando Bustamante. Maracay. Fundo Rostan Soares; doc.RS/DT/SC 19520640. (Casa de Oswaldo Cruz, Fundação Oswaldo Cruz). 17 jun. 1957.

GABALDÓN, Arnoldo.

Carta a Fernando Bustamante. Maracay. Fundo Rostan Soares; doc.RS/DT/SC 19520640. (Casa de Oswaldo Cruz, Fundação Oswaldo Cruz). 17 fev. 1956.

GABALDÓN, Arnoldo.

Carta a Mario Pinotti. Maracay. Fundo Rostan Soares; doc.RS/DT/SC 19520640. (Casa de Oswaldo Cruz, Fundação Oswaldo Cruz). 6 mar. 1953.
GABALDÓN, Arnoldo.

Chemoprophylasis of Malaria by the association of an antimalarical drug to the sodium chlororide used daily in the preparation of meals. In: International Congress on Tropical Medicine and Malaria, 5., 1953. Proceedings: communications. S.1.: s.n. v.2. 1953. Fundo Rostan Soares; doc.RS/PI/RJ 19460829 (Casa de Oswaldo Cruz, Fundação Oswaldo Cruz). 1953.

GABALDÓN, Arnoldo.

Consideraciones sobre el futuro de la lucha antimalarica. Revista Brasileira de Malariologia e Doenças Tropicais, Rio de Janeiro, v.4, n.4, p.307-318. 1952.

\section{GUTIERRREZ, A.T.}

Tiempos de guerra y paz: Arnoldo Gabaldón y la investigación sobre malaria en Venezuela, 1936-1990. Caracas: Editora Universitária. 1988.

HOCHMAN, Gilberto.

O sal como solução?: políticas de saúde e endemias rurais no Brasil (1940-1960). Sociologias, Porto Alegre, ano 12, n.24, p.158-193. 2010.

HOCHMAN, Gilberto.

O Brasil não é só doença: o programa de saúde pública de Juscelino Kubitschek. História, Ciências, Saúde - Manguinhos, Rio de Janeiro, n.16, supl.1, p.313-331. 2009.

HOCHMAN, Gilberto.

From autonomy to partial alignment: national malaria programs in the time of global eradication, Brazil, 1941-61. Canadian Bulletin of Medical History/Bulletin Canadien d'Histoire de la Médecine, St. John's, v.25, n.1, p.161-192. 2008.

HOCHMAN, Gilberto.

Mario Pinotti. In: Bynum, W.F.; Bynum, H. Dictionary of medical biography, v. 4, Westport: Greenwood Press. v.4, p.1013. 2007.

HOCHMAN, Gilberto; MELLO, Maria Teresa Bandeira de; SANTOS, Paulo Roberto Elian dos. A malária em foto: imagens de campanhas e ações no Brasil da primeira metade do século XX. História, Ciências, Saúde - Manguinhos, Rio de Janeiro, v.9, supl., p.233-273. 2002.

HUMPHREYS, M.

Kicking a dying dog: DDT and the demise of malaria in the American South, 1942-1950. Isis, Chicago, v.87, n.1, p.1-17. 1996.

KOENIG, Karl.

Carta a Emilio J. Pampana. Bayerwerk, Leverkusen. Fundo Rostan Soares; doc.RS/DT/ SC 19520640. (Casa de Oswaldo Cruz, Fundação Oswaldo Cruz). 10 out. 1957. 
MORAES, Hélbio Fernandes.

A luta contra a malária no Brasil. In: Moraes, Hélbio Fernandes. SUCAM: sua origem, sua história. Brasília: Ministério da Saúde. v.2, p.405-471. 1990.

MYRDAL, Gunnar.

Economics aspects of health. WHO Chronicle, Geneva, v.6, n.204, p.224-242. 1952.

NOTICIÁRIO.

Revista Brasileira de Malariologia e Doenças

Tropicais, Rio de Janeiro, v.10, n.2, p.213-216. 1958.

\section{NOVAS DESCOBERTAS..}

Novas descobertas da ciência brasileira.

A Notícia, Rio de Janeiro. Fundo Rostan Soares, doc.RS/DI/RJ 19460829. (Casa de Oswaldo Cruz, Fundação Oswaldo Cruz). 2 dez. 1953.

PACKARD, Randall M.

The making of a tropical disease: a short history of malaria. Baltimore: Johns Hopkins

University Press. (Johns Hopkins Biographies of Disease). 2007.

PACKARD, Randall M.

'No other logical choice': global malaria eradication and the politics of international health in the Post-War Era. Parassitologia, Roma, v. 40, n.1-2, p.217-229. 1998.

PACKARD, Randall M.

Malaria dreams: postwar visions of world. Medical Anthropology, New York, v.17, p.279-296, 1997.

PAHO/WHO.

Pan American Health Organization/World Health Organization. VIII Report on the status of malaria eradication in the Americas.

Trabalho apresentado no Meeting Pan American Sanitary Organization, 12., and Meeting World Health Organization, 12., sept. 1960, Washington. 1960.

\section{$\mathrm{PAHO} / \mathrm{WHO}$}

Pan American Health Organization/World Health Organization. VII Report on the status of malaria eradication in the Americas. Presented at: Meeting Pan American Sanitary Organization, 11., and Meeting World Health Organization, 11, sept. 1959, Washington. 1959.

PAMPANA, Emilio J.

Carta a Mario Pinotti. S.l. Fundo Rostan Soares; doc.RS/DT/SC 19520640. (Casa de Oswaldo Cruz, Fundação Oswaldo Cruz). 18 maio 1957.

PAMPANA, Emilio J.

Carta a Mario Pinotti. S.l. Fundo Rostan Soares; doc.RS/DT/SC 19520640. (Casa de
Oswaldo Cruz, Fundação Oswaldo Cruz). 8 mar. 1957.

PAULINI, Ernest.

O passado revisitado: o Instituto de Malariologia e o Instituto de Endemias Rurais (INERu). História, Ciências, Saúde - Manguinhos, Rio de Janeiro, v.11, n.1, p.143-158. 2004.

PAYNE, David.

Did medicated salt hasten the spread of chloroquine resistance in Plasmodium falciparum?. Parasitology Today, Cambridge, v.4, n.4, p.112-115. 1988.

PINOTTI, Mario.

Vida e morte do brasileiro: saúde e doença no Brasil de 1959. Rio de Janeiro: Civilização Brasileira. 1959.

PINOTTI, Mario.

Instalação do grupo de trabalho constituído para erradicação da Malária no Brasil. Revista Brasileira de Malariologia e Doenças Tropicais, Rio de Janeiro, v.10, n.2, p.213-220. 1958.

PINOTTI, Mario.

Carta a Emilio J. Pampana. Rio de Janeiro. Fundo Rostan Soares; doc.RE/PI/RJ 9002040/3. (Casa de Oswaldo Cruz, Fundação Oswaldo Cruz). 14 nov. de 1957.

PINOTTI, Mario.

Carta a Emilio J. Pampana. Rio de Janeiro. Field Research on the Administration of an Antimalarical Drug (Chloroquine) mixed with salt, file M2/157/2 (WHO Archives).

11 jul. 1957.

PINOTTI, Mario.

O sal de cozinha como veículo de medicamentos antimaláricos: um método brasileiro de profilaxia do impaludismo: sua importância na erradicação da doença. Memória inédita apresentada para concorrer a uma vaga de membro titular da Academia Nacional de Medicina. Rio de Janeiro. Fundo Rostan Soares, subsérie Sal Cloroquinado, doc.RS/PI/TT/19572040. (Casa de Oswaldo Cruz, Fundação Oswaldo Cruz). 1957.

PINOTTI, Mario.

Discurso. In: Congresso Brasileiro de Higiene, 13., 12-16 ago. 1956, Fortaleza. Anais... S.l.: s.n. p.138. 1956a.

\section{PINOTTI, Mario.}

A importância atual do problema das endemias rurais do Brasil. Anais da Faculdade Fluminense de Medicina, Rio de Janeiro, v.4, p.1-8. 1956b.

PINOTTI, Mario; SOARES, Rostan. A erradicação da malária com o sal cloroquinado. Revista Brasileira de Malariologia e Doenças Tropicais, Rio de Janeiro, v.8, n.1, p.2-20. 1956. 
PORTUGAL, Henrique Furtado.

A saúde pública nas serras, altiplanos, sertões e gerais: textos de Henrique Furtado Portugal. Belo Horizonte: s.n. 2008.

\section{PROGRAMA...}

Programa de saúde pública do candidato Juscelino Kubitschek, 1955. São Paulo: L. Nicollini. 1955.

RACHOU, René G.

O Método Pinotti nas atuais campanhas de combate à malária. Revista Brasileira de Malariologia e Doenças Tropicais, Rio de Janeiro, v.12, n.2, p.329-337. 1960.

RACHOU, René G.

Atual estratégia da luta contra a malária. Revista Brasileira de Malariologia e Doenças Tropicais, Rio de Janeiro, Publicações Avulsas, n.4, p.3-25. 1956.

RUSSELL, Edmund.

War and nature: fighting humans and insects with chemicals from World War I to Silent Spring. Cambridge: Cambridge University Press. (Studies in Environment and History). 2001.

RUSSELL, Paul F.

Man's mastery of malaria. London: Oxford University Press. 1955.

SAMPAIO, Regina.

Ademar de Barros e o PSP. São Paulo: Global. 1982.

SIDDIQI, Javed.

World Health and world politics: the World Health Organization and the UN system. London: Hurst. 1995.

SILVA, Alexandra de Mello.

Desenvolvimento e multilateralismo: um estudo sobre a operação pan-americana no contexto da política externa de JK. Contexto Internacional, Rio de Janeiro, v.14, n.2, p.209-239. 1992.

SLATER, Leo B.

War and disease: biomedical research on malaria in the twentieth century, critical issues in health and medicine. New Brunswick: Rutgers University Press. 2009.

SLATER, Leo B.

Malaria chemotherapy and the 'kaleidoscopic' organisation of biomedical research during World War II. Ambix, s.l., v.51, n.2, p.107-134. 2004.

SNOWDEN, Frank M.

The conquest of malaria: Italy, 1900-1962. New Haven: Yale University Press. 2006.
SOARES, Rostan.

Objetivos da pesquisa sobre o sal cloroquinado e o programa adotado nas observações com doentes de malária hospitalizados. S.l. Fundo Rostan Soares; doc.RS/PI/RJ 19460829. (Casa de Oswaldo Cruz, Fundação Oswaldo Cruz). 1955.

SOARES, Rostan, PINOTTI, Mario.

Um novo método de profilaxia da malária. Associação de uma droga antimalárica ao sal de cozinha usado na alimentação diária. Trabalho apresentado no 11. Congresso Brasileiro de Higiene, 15-21 nov. 1953, Curitiba. Fundo Rostan Soares, doc.RS/PI/RJ 19460829 (Casa de Oswaldo Cruz, Fundação Oswaldo Cruz). 1953.

SPIELMAN, Andrew.

Ethical dilemmas in malaria control. Journal of Vector Ecology, Santa Ana, v.31, n.1, p.1-8. 2006.

VERDRAGER, Jacques

Localized permanent epidemics: the genesis of chloroquine resistance in plasmodium falciparum. Southeast Asian Journal of Tropical Medicine and Public Health, Bangkok, v.26, n.1, p.23-28. 1995.

VIZENTINI, Paulo Fagundes.

Juscelino Kubitschek: do retrocesso à barganha. In: Relações exteriores do Brasil (1945-1964): o nacionalismo e a política externa independente. Petrópolis: Vozes. p.89-121. 2004.

WHO.

World Health Organization. The Darling Foundation. Disponível em: http://www.who. int/governance/awards/darling/en/. Acesso em: 19 fev. 2010. s.d.

WINCKEL, C.W.F.

Carta a Mario Pinotti. S.l. Fundo Rostan Soares, doc.RS/DT/SC 19520640. (Casa de Oswaldo Cruz, Fundação Oswaldo Cruz). 7 out. 1954.

WINSLOW, C.E.A.

Lo que cuesta la enfermedad y lo que vale la salud. Washington: Organización Panamericana de la Salud. (OPS. Publicación Científica, 16). 1955.

WYETH.

Wieth Indústria Farmacêutica. História. Disponível em: http://www.wyeth.com.br/br/ historia.htm>. Acesso em: 10 jul. 2008. s.d.

ZALIS, Mariano.

Malaria drug resistance. Ciência e Cultura, Campinas, v.52, n.4-5, p.213- 219. 2000.

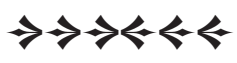

